\title{
Population Dynamics and Life History of Locusta migratoria tibetensis Chen in Lhasa River
}

\author{
Bhandari Jyoti ${ }^{1,2}$, Yasen Shali ${ }^{3}$, Zhang Zehua ${ }^{4}$, Yao Xiaoho ${ }^{5}$, Deng Jiang ${ }^{3}$, \\ Zhang Yaling ${ }^{5}$, Wang Cuiling ${ }^{5}$, Li Yang ${ }^{5}$, Lei Xueping ${ }^{5}$, Wang Wenfeng ${ }^{5}$, \\ Mohammad Farooque Hassan ${ }^{6}$ and Li Can ${ }^{1, *}$ \\ ${ }^{1}$ Provincial Key Laboratory for Rare Animals and Economic Insects of the \\ mountains of Guizhou Province, School of Biological and Environmental \\ Engineering, Guiyang University, Guiyang 550005, China \\ ${ }^{2}$ Institute of Forestry, Tribhuvan University, Pokhara Campus 43, Pokhara, Nepal \\ ${ }^{3}$ Xinjiang Agricultural University, Urumqi, 830052, China \\ ${ }^{4}$ State Key Laboratory for Biology of Plant Diseases and Insect Pests/Institute of \\ Plant Protection, Chinese Academy of Agricultural Sciences, Beijing 100193, China \\ ${ }^{5}$ Tibet Autonomous Region Academy of Agriculture and Animal Husbandry, Research \\ Institute, Lhasa, Tibet, 850032, China \\ ${ }^{6}$ Shaheed Benazir Bhutto University of Veterinary and Animal Sciences, Sakrand \\ Sindh, Pakistan
}

\section{A B S T R A C T}

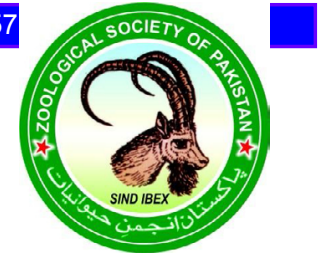

CrossMark

Article Information
Received 21 December 2018
Revised 13 March 2019
Accepted 10 April 2019
Available online 28 February 2020
Authors' Contribution
YS, ZY, ZZ and YX carried out the
field work and collected the data. WW,
LY and LX analyzed the data and
prepared the results. DJ, BJ, CL and
MFH wrote the manuscript with the
help of YS, ZY, ZZZ, YX, WW, LY
and LX.
Key words
Locusta migratoria tibetensis Chen,
population dynamics, life history,
spatial distribution pattern

Received 21 December

Revised 13 March 2019

Accepted 10 April 2019

Authors' Contribution

YS, ZY, ZZ and YX carried out the field work and collected the data. prepared the results. DJ, BJ, CL and MFH wrote the manuscript with the help of YS, ZY, ZZZ, YX, WW, LY their spreading, a clear understanding on the species traits is necessary. In this study, the population dynamics, life history and spatial distribution pattern of $L . m$. tibetensis Chen were explored on meadow and farmland of the Tibetan plateau during 2012. The first objective of this study was to investigate the population dynamic and life history of this pest on their outbreak sites. The second objective was to analyze the spatial distribution pattern of L. m. tibetensis Chen on both meadow and farmland. The lowest and highest population densities in meadow were recorded in early May and mid June respectively whereas in farmland lowest was recorded in late June and highest was in early June. The average population density in meadow was $3.1 \mathrm{~m}^{-2}$ and in farmland was $4.52 \mathrm{~m}^{-2}$. Reproduction takes place during summer (June/ July), generating two incomplete generations a year in meadow and one generation a year in farmland. The Iwao's $\mathrm{M}^{*}-\mathrm{m}$ regression analysis, Taylor's power law and aggregation cause analysis showed an aggregated distribution pattern for $L$. m. tibetensis Chen. It is concluded that insect behavior and environmental conditions co-influence the population density and spatial distribution pattern of this pest.
Key words population dynamics, life history, spatial distribution pattern

\section{INTRODUCTION}

$L$ ocusta migratoria tibetensis Chen belongs to Acridoidea, Oedipodidae, a new subspecies named by Chen (1963). This species was recorded only in China and its distribution area includes northern part of Qinghai, Tibet and west of Sichuan province (Chen, 1963). The $L$. $m$. tibetensis Chen inhabitants of the Tibetan plateau have common features and characteristics with those migratory locusts which are distributed at highest altitude (Feng, 2011). It is considered the most destructive endemic pests, as it destroys large amount of crops such as barely, wheat, corn, beans and other vegetation (Tu, 2012) and causes great loss in resources. Therefore it is essential to developed environmentally safe, long lasting and effective bio control methods for the management of pests (Gokturk et al., 2018).

\footnotetext{
* Corresponding author: lican790108@163.com 0030-9923/2020/0003-0927 \$ 9.00/0

Copyright 2020 Zoological Society of Pakistan
}

Identifying population densities of pest is one of the main component in pest management programs because this will help to estimate their effects on agricultural ecosystems (Kogan and Herzog, 1980). Study on population dynamics and life history of pests is important to accurately forecast their occurrences and to determine an effective control method. In addition, knowledge on the spatial distribution of insects is important in understanding the biology and ecology of a species and the basis for the development of sampling protocols (Bins and Nyrop, 2000).

The feeding preferences of $L$. $m$. tibetensis Chen vary greatly along with the development stage of instars. Yang et al. (2008) observed that $1^{\text {st }}$ and $3^{\text {rd }}$ instars prefer to feed on pasture grass whereas the $4^{\text {th }}$ instars prefer the highland barley and winter wheat. Also, the feeding habits of $L$. $m$. tibetensis Chen change with the availability of local seasonal vegetation.

Usually the locust population is regulated by temperature on the Tibetan plateau. Each year the number of generations of the locust species vary from one to five 
and this is dependent on temperature (Ma, 1958). Tibetan Plateau is gradually getting warmer at a higher rate than other places in China (Yao et al., 2000). Feng (2011) studied the responses of $L$. m. tibetensis Chen to climate warming over the Tibetan plateau, and found that there was a significant correlation between extent of potential distribution area and global warming. In addition, this study revealed that even a slight increase in temperature would cause great expansion in distribution of $L . m$. tibetensis Chen. Collectively, we know that temperature is closely associated with the population dynamics of locust species in the Tibetan plateau. As an endemic species in the upland area, L. m. tibetensis Chen has adapted to the topography, climate and vegetation of the plateau (Huang et al., 1981).

The locusts are mostly reported to grow in floodplains, lake overbanks, swamps, and coastal lowlands in eastern China (Yu, 2009). Soil with moisture content 10- 20\% is most favorable for laying of eggs, but 15 continuous days of submergence in water can destroy $100 \%$ of locust eggs (Wu et al., 1990). Therefore, according to the locust bioecology, wetlands are favorable sites for locusts to develop and dry conditions in spring and summer are important for locust outbreaks.

Although the geographical distribution, the responses to climate warming and biological characteristic of the $L$. $m$. tibetensis Chen in Tibetan plateau have been studied (Chen, 1963; Li, 2007; Feng et al., 2012; Tu et al., 2012; Chen et al., 1999), there is still severe knowledge shortage on its population dynamics; spatio-temporal dynamics, and life history, of locust populations. We need to enhance our knowledge on the reasons causing locust outbreaks and dramatic increases in population sizes, by which we can improve our locust management strategy, decrease the related cost and direct the local crop production to a sustainable way (Symmons, 2009; Lecoq, 2005). Therefore this study was undertaken to investigate the population dynamic and life history of L. m. tibetensis Chen in meadow and farmland and also to identify its spatial distribution pattern on the Tibetan plateau.

\section{MATERIALS AND METHODS}

Study site

In the present study we took samples from two different locations of the Lhasa region. The first experiment plot was selected from a farm land (Yangda, of Doilungdêqên County) in Lhasa (2940'40.94" N, 9055'1.95"), with an elevation of $3703 \mathrm{~m}$. The second experiment plot was selected at meadow land of Lhasa $\left(29^{\circ} 40^{\prime} 40.94\right.$ 'N, 90 $\circ 55^{\prime} 1.95$ ') at the elevation of $3641 \mathrm{~m}$. Both sample sites received intermediate day length sunshine, and under the influence of semiarid climates.

\section{Temperature measurement}

At each plot, HOBO temperature data loggers were deployed to record below ground soil temperature at $5 \mathrm{~cm}$ and $10 \mathrm{~cm}$ depths. Air temperature was measured at $25 \mathrm{~cm}$ height from surface ground at one hour interval. Both the above and below ground temperature was measured from late April to late September.

\section{Investigation of population characteristics in field}

To determine ecotype, density and development progress of $L$. $m$. tibetensis Chen, we conducted a census in two trials every three days from early May to late August in 2012. Checkerboard like bottomless frame method was used for sampling. We established 100 sampling frames at each site. Finally we counted the total number of insects, categorized and counted number of insects with different age group, number of insects based on spatial distribution pattern (gregarious type insects and solitary type) and vegetation types.

\section{Data analysis}

We investigated the hatching conditions of locust eggs and the development progress of nymphs and adults in different habitats from late April and generated a life history table of L. m. tibetensis Chen. We calculated the average density, standard deviation, variance and standard deviation per unit area of $L$. m. tibetensis Chen, then we used Excel software to generate graphs of population dynamics.

The spatial distribution of $L . m$. tibetensis Chen was determined through three methods: the Aggregation indices method, Taylor's power law and Iwao's regression methods.

Table I. Population aggregation indices criteria.

\begin{tabular}{llllll}
\hline Distributed & $\mathbf{I}$ & $\mathbf{M} * \mathbf{m}$ & $\mathbf{C a}$ & $\mathbf{C}$ & $\mathbf{K}$ \\
\hline Random distribution & $=0$ & $=1$ & $=0$ & $=1$ & $\rightarrow+\infty$ \\
Uniform distributed & $<0$ & $<1$ & $<0$ & $<1$ & $<0$ \\
Aggregated distribution & $>0$ & $>1$ & $>0$ & $>1$ & $>0$ \\
\hline
\end{tabular}

$\mathrm{I}$, clumping index; $\mathrm{M}^{*}$, mean crowding degree; $\mathrm{m}$, average density; $\mathrm{M}^{*}$ $\mathrm{m}^{-1}$, aggregation index; $\mathrm{Ca}$, Kuno index; $\mathrm{C}$, diffusion coefficient; $\mathrm{K}$, negative binomial distribution index.

\section{Aggregation indices method}

We counted up every resource unit's average worm amount $(\mathrm{m})$ and the sample variance $\left(\mathrm{s}^{2}\right)$ in each plot (Table I). The following aggregation indices were calculated:

(1) The clumping index I proposed by David and Moore (1954): 


$$
I=\frac{S^{2}}{m}-1
$$

When $\mathrm{I}<0$, uniform distribution; When $\mathrm{I}>0$, aggregated distribution; When $\mathrm{I}=0$, random distribution.

(2) Mean-crowding degree $\left(\mathrm{M}^{*}\right)$ and Lloyd (1967) $\left(\mathrm{M}^{*} / \mathrm{m}\right)$

$$
M^{*}=m+\left(\frac{S^{2}}{m}-1\right)
$$

When $\mathrm{M}^{*}>\mathrm{m}$, aggregated distribution; When $\mathrm{M}^{*}<\mathrm{m}$, uniform distribution; When $\mathrm{M}^{*}=\mathrm{m}$, random distribution. $M^{*} / \mathrm{m}$ is an aggregation index; $M^{*}$ stands for meancrowding degree; so $\mathrm{M}^{*} / \mathrm{m}$ is the ratio of mean crowding degree and average density. When $\mathrm{M}^{*} / \mathrm{m}>1$, aggregated distribution; When $\mathrm{M}^{*} / \mathrm{m}<1$, uniform distribution; When $\mathrm{M}^{*} / \mathrm{m}=1$, random distribution.

(3) Kuno (1968) index Ca:

$$
C_{a}=\frac{\left(\frac{S^{2}}{m}-1\right)}{m}
$$

When $\mathrm{Ca}<0$, uniform distribution; When $\mathrm{Ca}>0$, aggregated distribution; When $\mathrm{Ca}=0$, random distribution.

( 4 ) The diffusion coefficient $\mathrm{C}$ :

$$
C=\frac{S^{2}}{m}
$$

When $\mathrm{C}>1$, aggregated distribution; when $\mathrm{C}=1$, random distribution; when $\mathrm{C}<1$, uniform distributed.

(5) The negative binomial distribution index $\mathrm{K}$ :

$$
K=\frac{m^{2}}{\left(S^{2}-m\right)}
$$

When $\mathrm{k}<0$, uniform distribution; When $\mathrm{K} \rightarrow+\infty$, random distribution; When $\mathrm{K}>0$, aggregated distribution.

Taylor's power law (Taylor, 1961)

Taylor's power law was calculated as follows:

$$
\mathrm{s}^{2}=\log \mathrm{a}+\mathrm{b} \log \mathrm{m}
$$

Where $\mathrm{s}^{2}$ is sample variance, $\mathrm{m}$ is average density; $a$ is scaling factor related to sample size (Southwood and Henderson, 2000) and the slope b is an index of aggregation.

When $\log a=0, b=1$, the population is randomly distributed in all density; When $\log a>0, b=1$, the population distribution is aggregated in all density, but aggregation degree doesn't depend on density; When Log $\mathrm{a}>0, \mathrm{~b}>1$, the population distribution is aggregated in all density, and is density dependent; When $\log a<0$, $\mathrm{b}<1$, the higher population density, the more uniform distribution.

\section{Iwao's regression (Iwao, 1968)}

$$
\mathrm{M}^{*}=\alpha+\beta \mathrm{m}
$$

$\mathrm{M} *-\mathrm{m}$ regression method can be used to measure the spatial distribution pattern of multiple populations of the same species. For the regression equation $\mathrm{M} *=$ $\alpha+\beta \mathrm{m}, \alpha$ and $\beta$ can measure population spatial distribution pattern, and $\alpha$ describes the basic components of individual distribution. When $\alpha=0$, the basic component of distribution is a single individual; When $\alpha>0$, due to the mutual attraction between individuals, the basic component of distribution is individual group; When $\alpha<0$, the basic component of distribution is a single individual, but mutually exclusive between individuals. $\beta$ describes the spatial distribution pattern of basic components, when $\beta$ $=1$, random distribution; When $\beta<1$, uniform distribution; When $\beta>1$, aggregated distribution.

\section{Population aggregation cause analysis}

The mean population aggregation index $(\lambda)$ was calculated by using the following formula.

$$
\lambda=\frac{m}{2 K} \times r
$$

Where $\mathrm{m}$ stands for an average density (head/ samples), $\mathrm{K}$ stands for negative binomial distribution parameter, $r$ stands for degree of freedom which is equal to $2 \mathrm{~K}$ of a $\chi^{2}$ distribution function ( $\alpha=0.5$ significant levels). Due to $2 \mathrm{~K}$ freedom is often a decimal, $\chi^{2}$ value is often estimated by the proportional interpolation method. When $\lambda<2$, the aggregation reasons are likely to be caused by environmental conditions (climate, temperature, natural enemies, etc.), rather than gathering activities of insect itself; When $\lambda \geq 2$, the aggregation reason is caused by the insect behavior or environmental conditions or both.

\section{RESULTS AND ANALYSIS}

\section{Climatic characteristics}

Soil temperature is one of the most important conditions for the occurrence and development of $L$. $m$. tibetensis Chen. Figure 1 illustrates the change in temperature of spawning location of L. m. tibetensis Chen. In our study sites the highest temperature was $17.7^{\circ} \mathrm{C}$ and the minimum temperature was $10.24^{\circ} \mathrm{C}$. From April $28^{\text {th }}$ to May $6^{\text {th }}$ temperature was below $11^{\circ} \mathrm{C}$, the highest temperature occurred on May $30^{\text {th }}$. From September $11^{\text {th }}$ the temperature began to decline significantly.

Figure 2 shows the surface temperature of the time period from May $15^{\text {th }}$ to September $24^{\text {th }}$. The highest surface temperature recorded at the height of $25 \mathrm{~cm}$ was $22.18^{\circ} \mathrm{C}$ during mid June and lowest temperature was $13.1^{\circ} \mathrm{C}$ recorded at mid September. The highest humidity percentage was $87.74 \%$ during late August whereas lowest $37.24 \%$ was recorded in late May. 


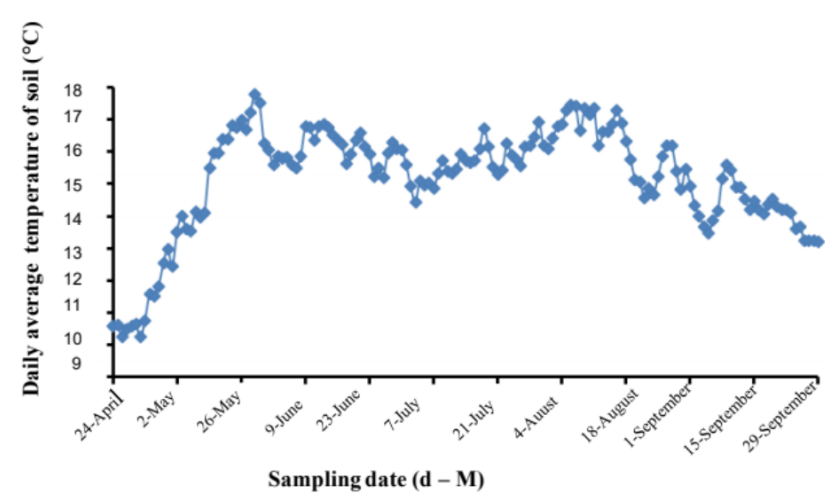

Fig. 1. Temperature of. Locusta migratoria tibetensis Chen's spawning sites.

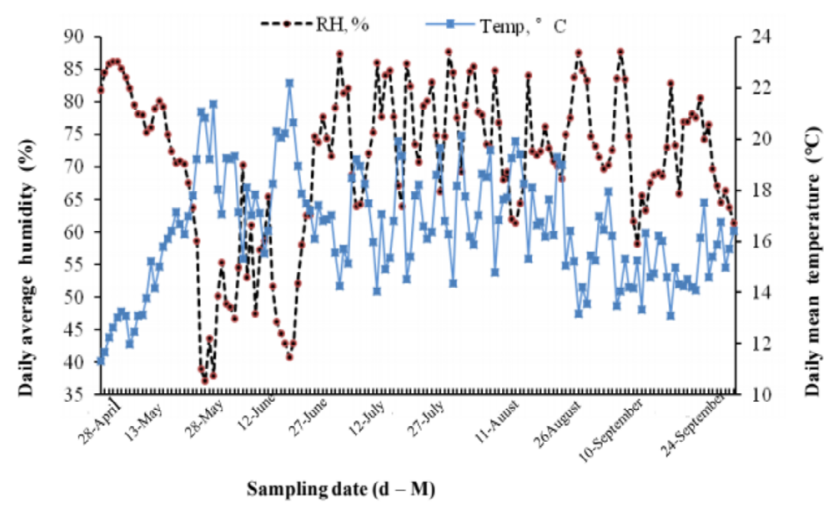

Fig. 2. The surface temperature and humidity at the height of $25 \mathrm{~cm}$ in Lhasa region.

\section{Population dynamics}

Figure 3 shows that the first instars appeared in meadow in early May. As temperatures rose to peak until end of May and early June, the population density increased rapidly and reached maximum in early June. After early June population density started to decrease gradually until end of August and density reduced to zero in the beginning of September. In farm land the first instars appeared from late May and population density increased rapidly until early June. After early June the population density decreased sharply until mid of June and again population density rose sharply during early July for short period. After early July population density reduced drastically until mid of July. From late July population density started to decrease until the end of August. Although the first instars appeared one month earlier in meadow land than in farmland, the population density was found higher in farmland than meadow land. The average population density in meadow was $3.1 \mathrm{~m}^{-2}$ and in farmland was $4.52 \mathrm{~m}^{-2}$.

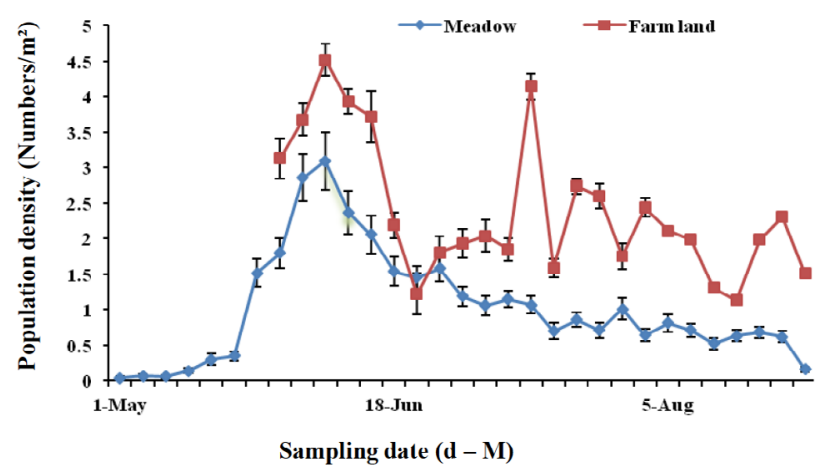

Fig. 3. Population dynamics of Locusta migratoria tibetensis Chen

\section{Natural population life history}

Table II shows the results of life history of $L . m$. tibetensis Chen in Lhasa river. In case of meadow land, hatching began in mid April, nymphs continued until late August, adults appeared from early June and continued to late October. The second generation of locust eggs hatched in early July and nymphs appeared during mid August. Due to drop down of temperature feathers could not develop completely, which caused natural death and discontinuing of the second generation. In the case of farmland, locust eggs of last year were hatched during late May, and the process of developing nymphs extended up to the end of August. Adult emergence appeared in early June, and continued until late October.

The spatial distribution pattern

\section{Determination of aggregated indices}

The results of aggregated indices tested in meadow (Table III) showed that in 26 sets of data measured, I (0.02 $\sim 4.31)>0, \mathrm{M} * / \mathrm{m}(1.02 \sim 4.74)>1, \mathrm{Ca}(0.02 \sim 3.74)>$ $0, \mathrm{C}(1.02 \sim 5.31)>1, \mathrm{~K}(0.27 \sim 41.80)>0$. All aggregated indices were in line with testing standards of aggregated distribution, indicating that L. m. tibetensis Chen had aggregated distribution in Lhasa river meadow.

The results of aggregated indices tested in farmland (Table IV) showed that in 24 sets of data measured, I ( 0.14 $\sim 8.62)>0, \mathrm{M} * / \mathrm{m}(1.08 \sim 3.19)>1, \mathrm{Ca}(0.08 \sim 2.19)>0$, $\mathrm{C}(1.14 \sim 9.62)>1, \mathrm{~K}(0.46 \sim 12.63)>0$, which indicated that L. m. tibetensis Chen had aggregated distribution in Lhasa river farmland.

\section{Iwao's $M^{*}-m$ regression analysis}

The regression equation of $L$. $m$. tibetensis Chen population in meadow is $\mathrm{M} *=2.3041 \mathrm{~m}-0.5275(\mathrm{R} 2=$ 
Table II. Life history of Locusta migratoria tibetensis Chen in meadow land and farmland of Lhasa river.

\begin{tabular}{|c|c|c|c|c|c|c|c|c|c|c|c|}
\hline 1 & 2 & 3 & 4 & 5 & 6 & 7 & 8 & 9 & 10 & 11 & 12 \\
\hline \multicolumn{12}{|c|}{ Meadow land } \\
\hline U M L & $\mathrm{U}$ M L & U M L & U M L & $\mathrm{U}$ M L & U M L & U M L & $\mathrm{U}$ M L & U M L & U M L & U M L & $\mathrm{U}$ M L \\
\hline \multirow[t]{5}{*}{$* * *$} & $* * *$ & $* * *$ & $* * *$ & $* * *$ & $* * *$ & $*$ & & & & & \\
\hline & & & -- & -- & --- & -- & --- & & & & \\
\hline & & & & & +++ & +++ & +++ & +++ & +++ & & \\
\hline & & & & & & & $* * *$ & $* * *$ & $* * *$ & $* * *$ & $* * *$ \\
\hline & & & & & & & -- & -- & -- & & \\
\hline \multicolumn{12}{|c|}{ Farmland } \\
\hline \multirow[t]{3}{*}{$* * *$} & $* * *$ & $* * *$ & $* * *$ & $* * *$ & $* * *$ & $*$ & & & & & \\
\hline & & & & - & -- & --- & -- & & & & \\
\hline & & & & & +++ & +++ & +++ & +++ & +++ & & \\
\hline
\end{tabular}

U, upper; M, middle; L, lower; *, locust eggs; -, nymphs; +, adult
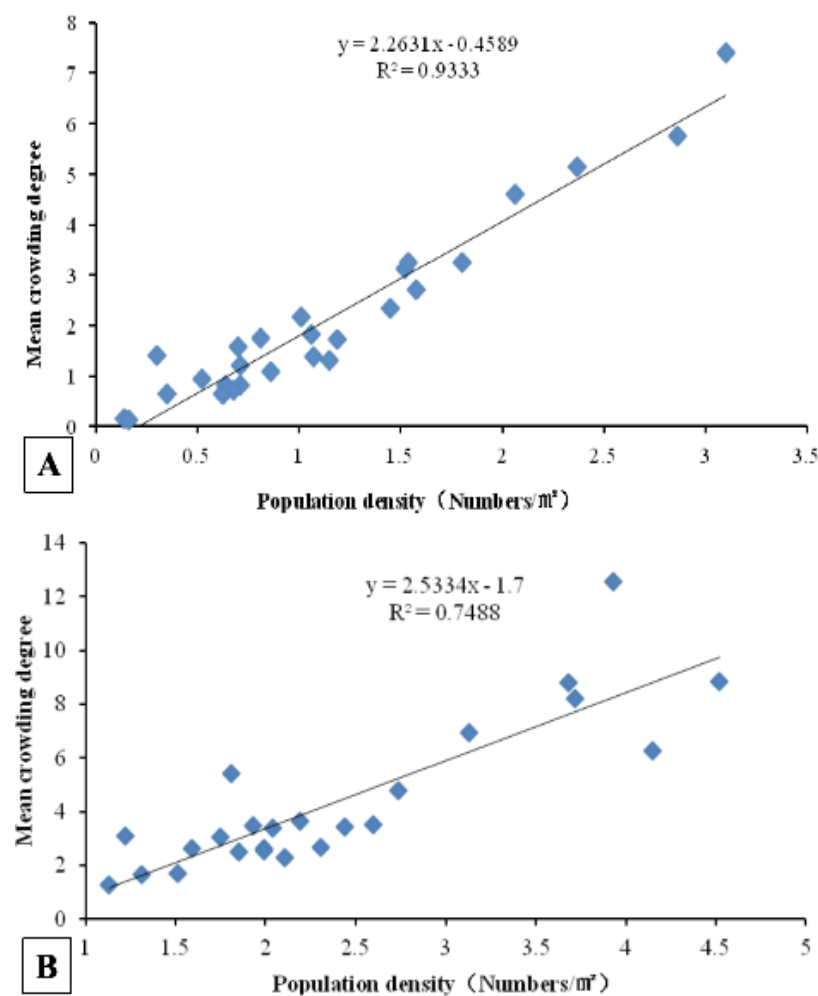

Fig. 4. Relationship between mean crowding and average population density of Locusta migratoria tibetensis Chen in meadowland (A) and in farmland (B) of Lhasa river.

0.9286), which was obtained by regression analysis of mean crowding Iwao $\left(\mathrm{M}^{*}\right)$ and average density $(\mathrm{m}) . \alpha<0$, $\beta>1$ means individuals in meadow is mutually exclusive, and the spatial distribution of basic components is aggregated. The coefficient of determination is 0.9286 , indicating ' $\mathrm{m}$ ' linearly explaining $92.86 \%$ of the total $\mathrm{M}^{*}$ variance (Fig. 4A).

The regression equation of $L . m$. tibetensis Chen population in farmland obtained through Iwao's method of using regression analysis of average crowding $\left(\mathrm{M}^{*}\right)$ and average density $(\mathrm{m})$ is: $\mathrm{M} *=2.5325 \mathrm{~m}-1.6972\left(\mathrm{R}^{2}\right.$ $=0.7487) . \alpha<0, \beta>1$ means individuals in farmland are mutually exclusive, and the spatial distribution of the basic components is aggregated. The mean density (m) explained $74.87 \%$ of the total $\mathrm{M}^{*}$ variance (Fig. $4 \mathrm{~B}$ ).

\section{Taylor's power law}

The relationship between variance and average density in meadow can be expressed by:

$$
\log s^{2}=0.2585+1.5742 \log m(R=0.9048)
$$

where $\log \mathrm{a}=0.2585>0, \mathrm{~b}=1.5742>1$ represent that the population is aggregated distribution in all density, and is density dependent.

The relationship between variance and average density in farmland is:

$$
\log \mathrm{s}^{2}=0.0231+2.0713 \log \mathrm{m}(\mathrm{R}=0.7901)
$$

Where $\log a=0.0231>0, b=2.0713>1$ represent the population is aggregated distribution in all density, and is density dependent.

\section{Population aggregation cause analysis}

For meadow, the mean population aggregation index ( $\lambda$ ) proposed by Blackith (1961) was used to analyze the reasons why $L$. $m$. tibetensis $C$ hen gathered. The average of 26 surveys is 1.20 , and mean $\mathrm{K}$ is 4.67 . In the chi-square table, freedom $2 \mathrm{~K}$ of $\chi 20.5$ corresponds with an $\mathrm{r}$ value 
of 38.88 . The $\lambda$ value of 4.99 , more than 2 , indicates the reasons for $L$. $m$. tibetensis Chen gathered in meadow are determined by insect behavior and environmental conditions at the same time.

Table III. Locusta migratoria tibetensis Chen aggregated indices in meadow land of Lhasa river.

\begin{tabular}{|c|c|c|c|c|c|c|c|c|}
\hline Date & $\mathbf{m}$ & $\mathbf{s}^{2}$ & $\mathbf{M}^{*}$ & I & $\mathbf{M} * / \mathbf{m}$ & $\mathrm{Ca}$ & C & $\mathbf{K}$ \\
\hline $5 / 17$ & 0.30 & 0.64 & 1.42 & 1.12 & 4.74 & 3.74 & 2.12 & 0.27 \\
\hline $5 / 21$ & 0.35 & 0.45 & 0.64 & 0.29 & 1.83 & 0.83 & 1.29 & 1.20 \\
\hline $5 / 25$ & 1.52 & 3.95 & 3.12 & 1.60 & 2.05 & 1.05 & 2.60 & 0.95 \\
\hline $5 / 29$ & 1.80 & 4.40 & 3.25 & 1.45 & 1.80 & 0.80 & 2.45 & 1.24 \\
\hline $6 / 2$ & 2.86 & 11.17 & 5.77 & 2.91 & 2.02 & 1.02 & 3.91 & 0.98 \\
\hline $6 / 6$ & 3.10 & 16.45 & 7.41 & 4.31 & 2.39 & 1.39 & 5.31 & 0.72 \\
\hline $6 / 10$ & 2.37 & 8.96 & 5.15 & 2.78 & 2.17 & 1.17 & 3.78 & 0.85 \\
\hline $6 / 14$ & 2.06 & 7.29 & 4.60 & 2.54 & 2.23 & 1.23 & 3.54 & 0.81 \\
\hline $6 / 18$ & 1.54 & 4.19 & 3.26 & 1.72 & 2.12 & 1.12 & 2.72 & 0.89 \\
\hline $6 / 22$ & 1.45 & 2.76 & 2.35 & 0.90 & 1.62 & 0.62 & 1.90 & 1.61 \\
\hline $6 / 26$ & 1.58 & 3.36 & 2.70 & 1.12 & 1.71 & 0.71 & 2.12 & 1.40 \\
\hline $6 / 30$ & 1.19 & 1.83 & 1.73 & 0.54 & 1.45 & 0.45 & 1.54 & 2.21 \\
\hline $7 / 4$ & 1.06 & 1.88 & 1.83 & 0.77 & 1.73 & 0.73 & 1.77 & 1.38 \\
\hline $7 / 8$ & 1.15 & 1.34 & 1.32 & 0.17 & 1.14 & 0.14 & 1.17 & 6.93 \\
\hline $7 / 12$ & 1.07 & 1.40 & 1.38 & 0.31 & 1.29 & 0.29 & 1.31 & 3.48 \\
\hline $7 / 16$ & 0.70 & 1.32 & 1.59 & 0.89 & 2.27 & 1.27 & 1.89 & 0.79 \\
\hline $7 / 20$ & 0.86 & 1.05 & 1.08 & 0.22 & 1.26 & 0.26 & 1.22 & 3.87 \\
\hline $7 / 24$ & 0.71 & 1.08 & 1.23 & 0.52 & 1.73 & 0.73 & 1.52 & 1.37 \\
\hline $7 / 28$ & 1.01 & 2.19 & 2.18 & 1.17 & 2.16 & 1.16 & 2.17 & 0.86 \\
\hline $8 / 1$ & 0.64 & 0.76 & 0.82 & 0.18 & 1.29 & 0.29 & 1.18 & 3.47 \\
\hline $8 / 5$ & 0.81 & 1.57 & 1.75 & 0.94 & 2.16 & 1.16 & 1.94 & 0.86 \\
\hline $8 / 9$ & 0.71 & 0.79 & 0.83 & 0.12 & 1.17 & 0.17 & 1.12 & 6.01 \\
\hline $8 / 13$ & 0.52 & 0.74 & 0.94 & 0.42 & 1.80 & 0.80 & 1.42 & 1.25 \\
\hline $8 / 17$ & 0.63 & 0.64 & 0.65 & 0.02 & 1.02 & 0.02 & 1.02 & 41.80 \\
\hline $8 / 21$ & 0.68 & 0.70 & 0.72 & 0.04 & 1.05 & 0.05 & 1.04 & 18.76 \\
\hline $8 / 25$ & 0.62 & 0.64 & 0.66 & 0.04 & 1.06 & 0.06 & 1.04 & 17.46 \\
\hline
\end{tabular}

$\mathrm{I}$, clumping index; $\mathrm{M}^{*}$, mean crowding degree; $\mathrm{m}$, average density; $\mathrm{M}^{*}$ $\mathrm{m}^{-1}$, aggregation index; Ca, Kuno index; $\mathrm{C}$, diffusion coefficient; $\mathrm{K}$, negative binomial distribution index.

For farmland, the average of 24 surveys is 2.40 , and the mean $\mathrm{K}$ is 2.87 . In the chi-square table, freedom $2 \mathrm{~K}$ of $\chi 20.5$ corresponds with an $r$ value of 36.415 . An $\lambda$ value of 15.22 , more than 2 , indicates that the reasons for $L$. $m$. tibetensis Chen gathered in meadow are determined by insect behaviors and environmental conditions at the same time.
Table IV. Locusta migratoria tibetensis Chen aggregated indices in farmland of Lhasa river.

\begin{tabular}{lllllllll}
\hline Date/month & $\mathbf{m}$ & $\mathbf{s}^{2}$ & $\mathbf{M}^{*}$ & $\mathbf{I}$ & $\mathbf{M} * \mathbf{m}$ & $\mathbf{C a}$ & $\mathbf{C}$ & $\mathbf{K}$ \\
\hline $5 / 29$ & 3.13 & 15.04 & 6.94 & 3.81 & 2.22 & 1.22 & 4.81 & 0.82 \\
$6 / 2$ & 3.68 & 22.50 & 8.79 & 5.11 & 2.39 & 1.39 & 6.11 & 0.72 \\
$6 / 6$ & 4.52 & 24.07 & 8.85 & 4.33 & 1.96 & 0.96 & 5.33 & 1.05 \\
$6 / 10$ & 3.93 & 37.82 & 12.55 & 8.62 & 3.19 & 2.19 & 9.62 & 0.46 \\
$6 / 14$ & 3.72 & 20.39 & 8.20 & 4.48 & 2.20 & 1.20 & 5.48 & 0.83 \\
$6 / 18$ & 2.19 & 5.37 & 3.64 & 1.45 & 1.66 & 0.66 & 2.45 & 1.51 \\
$6 / 22$ & 1.22 & 3.49 & 3.08 & 1.86 & 2.52 & 1.52 & 2.86 & 0.66 \\
$6 / 26$ & 1.81 & 8.36 & 5.43 & 3.62 & 3.00 & 2.00 & 4.62 & 0.50 \\
$6 / 30$ & 1.93 & 4.89 & 3.47 & 1.54 & 1.80 & 0.80 & 2.54 & 1.26 \\
$7 / 4$ & 2.04 & 4.79 & 3.39 & 1.35 & 1.66 & 0.66 & 2.35 & 1.52 \\
$7 / 8$ & 1.85 & 3.04 & 2.49 & 0.64 & 1.35 & 0.35 & 1.64 & 2.88 \\
$7 / 12$ & 4.15 & 12.88 & 6.25 & 2.10 & 1.51 & 0.51 & 3.10 & 1.97 \\
$7 / 16$ & 1.59 & 3.21 & 2.61 & 1.02 & 1.64 & 0.64 & 2.02 & 1.56 \\
$7 / 20$ & 2.74 & 8.32 & 4.77 & 2.03 & 1.74 & 0.74 & 3.03 & 1.35 \\
$7 / 24$ & 2.60 & 5.01 & 3.53 & 0.93 & 1.36 & 0.36 & 1.93 & 2.80 \\
$7 / 28$ & 1.75 & 4.03 & 3.05 & 1.30 & 1.74 & 0.74 & 2.30 & 1.34 \\
$8 / 1$ & 2.44 & 4.92 & 3.45 & 1.01 & 1.42 & 0.42 & 2.01 & 2.40 \\
$8 / 5$ & 2.11 & 2.46 & 2.28 & 0.17 & 1.08 & 0.08 & 1.17 & 12.63 \\
$8 / 9$ & 1.99 & 3.24 & 2.62 & 0.63 & 1.32 & 0.32 & 1.63 & 3.16 \\
$8 / 13$ & 1.31 & 1.75 & 1.65 & 0.34 & 1.26 & 0.26 & 1.34 & 3.89 \\
$8 / 17$ & 1.13 & 1.29 & 1.27 & 0.14 & 1.12 & 0.12 & 1.14 & 8.19 \\
$8 / 21$ & 1.99 & 3.06 & 2.53 & 0.54 & 1.27 & 0.27 & 1.54 & 3.70 \\
$8 / 25$ & 2.31 & 3.19 & 2.69 & 0.38 & 1.16 & 0.16 & 1.38 & 6.09 \\
$8 / 29$ & 1.51 & 1.81 & 1.71 & 0.20 & 1.13 & 0.13 & 1.20 & 7.65 \\
\hline & & & & & & & & \\
6 & & & & & &
\end{tabular}

\section{DISCUSSION}

\section{Life history}

L. m. tibetensis Chen's distribution depended strongly on temperature. Tu et al. (2012) indicated that L. m. tibetensis Chen mainly established itself under temperate zones. As most parts of Lhasa river regions fall under temperate condition, L. m. tibetensis Chen is reported only from this region on the Qinghai Tibetan plateau at present (Chen, 1963). There is strong influence of temperature on locust biology (Dudley, 1964; Begon, 1983), as it does in other insects (Chown and Nicolson, 2004). Effects of temperature on growth and development of L. migratoria species have been the subject of numerous studies (Jing et al., 2003; Feng et al., 2012). In the present study, field observations on the effects of temperature on population dynamic and life history were performed. Previous studies 
showed that the temperature needed for development of L. migratoria ranged from $10^{\circ} \mathrm{C}$ to $30^{\circ} \mathrm{C}$ (Hao et al., 2004; Quesada et al., 2000; Tu et al., 2012). This is consistent with our observation which shows that development phase of $L$. $m$. tibetensis Chen occurs within the surface temperature ranged from $11^{\circ} \mathrm{C}$ to $21^{\circ} \mathrm{C}$.

Most of the locust species hatch in a sequence from year to year, and their adults occur in different periods of summer (Kang et al., 1991). Our observation shows that hatching in meadow occurred approximately 20 days prior to those on the farmland. Several factors influence the hatching time in the life cycles of locust species (Kemp and Sanchez, 1987). Firstly, the amount of heat received by eggs depends upon the depth of the eggs in soil. Secondly, the seasons of oviposition during summer or autumn may also contribute to the differences in observed hatching time of the locust species. In this study the eggs of locust in farmland deposited in the late summer would not have received adequate heat during autumn to achieve diapause stage. Additionally, the outbreak of eggs might be disturbed by moisture stress and low temperature (Mukerji and Gage, 1978).

Temperature during early summer is critical to egg development. In our study area, the locust population produces two incomplete generations in meadow and one complete generation in farmland per year. This might be caused by stronger light intensity and higher temperature in meadow than in farmland. Studies of different plant species have showed that nitrogen allocation tends to parallel gradients of light availability (Hirose et al., 1989; Schimel et al., 1991; Ackerly, 1992). Thus, temperature could significantly affect the availability of host plant of locust in Tibetan plateau. However the potential distributions cannot be estimated based on climate alone. Beside temperature, soil moisture and foods are essential for successful hatching (Chladny, 1998; Jing et al., 2003; Ackonor, 1988). Locusts mainly lay their eggs in the ground and below the surface. Once the eggs are deposited, factor such as temperature, moisture, oxygen and ability to withstand adverse conditions are critical for their survival. Therefore there is also a need to consider other environmental and topographic factors in future study.

\section{Population dynamics}

The mean population density of $L . m$. tibetensis Chen, in our study was distinctly higher in farmland than in meadow. The observed higher population densities in farmland are likely to be somehow related to food availability and preference, resistance to insecticides, and reduction in natural predators. According to the observations in our study, a seasonal abundance pattern was prepared for the L. m. tibetensis Chen population. The first generation of population occurs during the late spring period (May) in meadow and early June in farmland. During summer, usually after June population densities fluctuate from moderate to high and highest annual density peaks are recorded at this time. From September population densities declines and its abundance decreases suddenly with winter. During the summer, the regular fluctuations in the population pattern in both meadow and farm land from monthly basis showed active responses and a fast growth, especially by young reproducers. Activity budgets of individual locust reveal that both local dispersal and feeding activity enhance with increasing temperature (White, 1974; Hewitt, 1979).

The second general pattern in meadow was observed during late autumn, low densities associated with low temperatures. Under low temperature, embryo develops slowly, which cause delay in hatching. Under severe winter, nymphs cannot develop. Low temperatures after hatch mostly result in slower growth rates, leaving nymphs vulnerable to environmental stresses for longer periods of time. Usually low temperature will cause locust to take longer time period to complete each developmental stage, which will affect their natural conditions, and lead them to be more vulnerable to time dependent sources of mortality (Roy et al., 2000). Due photoperiod, rainfall and food scarcity, the population dynamics of locust are negatively affected (Li et al., 1998; Kingsolver et al., 2006; Raworth and Schade, 2006). In our study it was observed that life cycle of $L$. m. tibetensis Chen is strongly coupled with temperature, and vegetation cover. Considering that temperature and vegetation as the main factor influencing the development of the L. m. tibetensis in the farmland, during summer, the farmer should develop variety of cultural and physical control methods to reduce the negative effect of $L$. m. tibetensis. For example use of pesticides with fire, burning roosting locusts at night, digging trenches and plowing fields infested with pods can be done.

\section{The spatial distribution pattern}

By using aggregated indices, Iwao's $M^{*}-\mathrm{m}$ regression analysis, Taylor's power law and aggregation cause analysis, we found that L. m. tibetensis Chen, in Lhasa river have aggregated distribution, and have density dependence. Similar studies have been conducted using different aggregation cause analysis (Arnaldo et al., 2005; Feng et al., 1992; Sedaratian et al., 2010). Naseri et al. (2009) analyzed the spatial distribution of Empoasca decipiens (Hemiptera: Cicadellidae) and found that the variance to mean ratio method resulted in an aggregated distribution for $E$. decipiens whereas the regression models of Taylor's power law and Iwao's patchiness 
resulted in a random distribution pattern, suggesting that the different statistical methods can generate distinct results and accuracies in calculating spatial distribution of $E$. decipiens. Although some characteristics such as population growth and reproduction differ from one generation to another, spatial distribution pattern is some extent constant (Taylor, 1984). Especially reproductive characteristics, feeding behavioral patterns and environment might result in aggregated distribution and density dependence characteristic of this pest population. Variation in plant composition and structure may also affect the spatial distribution of an insect (Sedaratian et al., 2010). therefore, intense research is needed to confirm the causes of spatial distribution of this pest in Lhasa river.

\section{CONCLUSIONS}

In this study, it has been demonstrated that the different habitat types (meadow and farmland) had significant effects on the population dynamics and spatial distribution pattern of Locusta migratoria tibetensis Chen. We found that the devastating effects caused by this pest are mostly concentrated from May to early September. During this time the pest population should be monitored every year and control measures can be planned in effective ways to destroy this pest. Especially biological control method is recommended to regulate the populations of $L$. m. tibetensis Chen for minimizing economic damage on agricultural product in the farmland.

\section{ACKNOWLEDGEMENTS}

The Academician Workstation of Guiyang University, Guizhou Province ([2019]5605); The Regional First-class Discipline Construction of Guizhou Province to GYU ([2017]85); Provincial Key and Special Subject of Guizhou Province-Ecology (ZDXK[2015]11) and The Training Project for High-Level Innovative Talents in Guizhou Province (2016 [4020]).

\section{Statement of conflict of interest}

The authors state that there is no conflict of interest.

\section{REFERENCES}

Arnaldo, P.S. and Torres, L.M., 2005. Spatial distribution and sampling of Thaumetopoea pityocampa (Den. \& Schiff.) (Lep. Thaumetopoeidea) populations on Pinus pinaster Ait. in Montesinho, N. Portugal. For. Ecol. Manage., 210: 1-7. https://doi.org/10.1016/j. foreco.2005.02.041

Ackerly, D.D., 1992. Light, leaf age and leaf nitrogen concentration in a tropical vine. Oecologia, 89: 596600. https://doi.org/10.1007/BF00317169

Ackonor, J.B., 1988. Effect of soil moisture and temperature on hatchling weight and survival in Locusta migratoria migratorioides (Reiche and Fairmaire). Int. J. Trop. Insect. Sci., 9: 625-628. https://doi.org/10.1017/S1742758400005117

Begon, M., 1983. Grasshopper populations and weather: the effects of insolation on Chorthippus brunneus. Ecol. Ent., 8: 361-370. https://doi. org/10.1111/j.1365-2311.1983.tb00516.x

Binns, M.R., Nyrop, J.P. and Werf, W., 2000. Sampling and monitoring in crop protection: The theoretical basis for developing practical decision guides. CABI. https://doi.org/10.1079/9780851993478.0000

Blackwith, R.E., 1958. Nearest neighbours distance measurements for the estimation of animal populations. Ecology, 39: 147-150. https://doi. org/10.2307/1929978

Chladny, T.A. and Whitman, D.W., 1998. The effects of temperature, soil moisture, and ventilation on the eggs of the grasshopper Romalea guttata. Trans. Ill. State. Acad. Sci., 91: 155-159.

Chen, Y.L., 1963. A new subspecies of Locusta migratoria-Tibetan migratory locust (Locusta migratoria tibetensis subsp. n.). Acta entomol. Sin., 12: 463-475.

Chen, Y.L. and Zhang D.E., 1999. Historical evidence for population dynamics of Tibetan migratory locust and the forecast of its outbreak. Insect Sci., 6: 135-145. https://doi.org/10.1111/j.1744-7917.1999.tb00160.x

Chown, S.L. and Nicolson, S., 2004. Insect physiological ecology: Mechanisms and patterns. Oxford University Press. https://doi.org/10.1093/ acprof:oso/9780198515494.001.0001

David, F.N. and Moore, P.G., 1954. Notes on contagious distributions in plant populations. Annls. Bot., 18: 47-53. https://doi.org/10.1093/oxfordjournals.aob. a083381

Dudley, B.A., 1964. Effects of temperature and humidity upon certain morphometric and colour characters of the desert locust (Schistocerca: gregaria Forskal) reared under controlled conditions. Trans. $R$. entomol. Soc. Lond., 116: 115-129. https://doi. org/10.1111/j.1365-2311.1964.tb00827.x

Feng, C.H., Guo, C., Luo, L.M. and Qin, Z., 2012. Response of Locusta migratoria tibetensis Chen (Orthoptera: Acrididae) to climate warming over the Tibetan plateau. J. appl. Ent., 136: 313-320. https:// doi.org/10.1111/j.1439-0418.2011.01659.X

Feng, C.H., Shan, X.N. and Guo, C., 2011. The change of potential distribution of Locusta migratoria 
tibetensis Chen (Orthoptera: Acrididae) from 1961 to 2005. Acta entomol. Sin., 54: 694-700. (in Chinese)

Feng, M.G. and Nowierski, R.M., 1992. Spatial distribution and sampling plans for four species of cereal aphids (Homoptera: Aphididae) infesting spring wheat in Southwestern Idaho. J. econ. Ent., 85: 830-837. https://doi.org/10.1093/jee/85.3.830

Guo, F., Chen, Y.L. and Lu B.L., 1989. The biology of the migratory locusts in China. Shandong Science and Technology Press, Jinan, China.

Gokturk, T., Elif, T. and Recep K., 2018. Prospects of entomopathogenic bacteria and fungi for biological control of Ricania simulans (Walker, 1851) (Hemiptera: Ricaniidae). Pakistan J. Zool., 50: 75-82. http://dx.doi.org/10.17582/journal. pjz/2018.50.1.75.82

Hao, S.G. and Kang, L., 2004. Effects of temperature on the post-diapause embryonic development and the hatching time in three grasshopper species (Orthoptera: Acrididae). J. appl. Ent., 128: 95-101. https://doi.org/10.1046/j.1439-0418.2003.00810.x

Huang F. S., Huang, C.M. and Liu, J.P., 1981. Studies on the acridoid fauna of Xizang and its evolution. Acta entomol. Sin., 3: 157-170. (In Chinese).

Hewitt, G.B., 1979. Hatching and development of rangeland grasshoppers in relation to forage, growth, temperature and precipitation. Environ. Ent., 8: 2429. https://doi.org/10.1093/ee/8.1.24

Hirose, T., Werger, M. and Van R.J., 1989. Canopy development and leaf nitrogen distribution in a stand of Carex acutiformis. Ecology, 70: 1610-1618. https://doi.org/10.2307/1938094

Iwao, S., 1968. A new regression method for analyzing the aggregation pattern of animal populations. Res. Popul. Ecol., 10: 1-20. https://doi.org/10.1007/ BF02514729

Jing, X.H. and Kang, L., 2003. Geographical variation in egg cold hardiness: A study on the adaptation strategies of the migratory locust Locusta migratoria L. Ecol. Ent., 28: 151-158. https://doi.org/10.1046/ j.1365-2311.2003.00497.x

Kang L., Li, H.C. and Zhang, Z.R., 1991. The geographical conditions for grassland insects in Nei Mongol. Grassland insect Inner Mongolia. 1-91. (In Chinese)

Kemp, W.P. and Sánchez, N.E., 1987. Differences in post diapause thermal requirements for eggs of two rangeland grasshoppers. Canad. Entomol., 119: 653-661. https://doi.org/10.4039/Ent119653-7

Kingsolver, J.G., Shlichta, G. and Ragland, G.J., 2006. Thermal reaction norms for caterpillar growth depends on diet. Evol. Ecol. Res., 8: 703-715.

Kogan, M. and Herzog, D.C., 1980. Sampling methods in soybean entomology. Springer Verlag, New York. (In Japanese ). https://doi.org/10.1007/9781-4612-9998-1

Kuno, E., 1968. Studies on the population dynamics of rice leaf hoppers in a paddy field. Bull. Kynshu Agric. Exp. Stat., 14: 131-246.

Lloyd, M., 1967. Mean crowding. J. Anim. Ecol., 36: 1-30. https://doi.org/10.2307/3012

Lecoq, M., 2005. Desert locust management: From ecology to anthropology. J. Orthop. Res., 14: $\quad 179-186 . \quad$ https://doi.org/10.1665/10826467(2005)14[179:DLMFET]2.0.CO;2

Li, Q., Feng, C.H., Zhang, M., Jiang, F., Yang, G. and Luo, L.M., 2007. The biological characteristics of Locusta migratoria tibetensis (Chen). Chin. Bull. Ent., 44: 210-213. (In Chinese).

Li, B.X., Chen, Y.L. and Cai, H.L., 1998. Effects of photoperiod on embryonic diapauses and reproduction in the migratory locust in three geographic populations. Ent. Sin., 5: 342-349. https://doi.org/10.1111/j.1744-7917.1998.tb00329.x

Ma, S.J., 1958. The population dynamics of the Oriental migratory locust (Locusta migratoria manilensis Meyen) in China. Acta Ent. Sin., 8: 1- 40.

Mukerji, M.K. and Gage, S.H., 1978. A model for estimating hatch and mortality of grasshopper egg populations based on soil moisture and heat. Ann. entomol. Soc. Am., 71: 183-190. https://doi. org/10.1093/aesa/71.2.183

Naseri, B., Fathipour, Y. and Talebi A.A., 2009. Population density and spatial distribution pattern of Empoasca decipiens (Hemiptera: Cicadellidae) on different bean species. J. agric. Sci. Technol., 11: 239-248.

Quesada-Moraga, E. and Santiago-Álvarez, C., 2000. Temperature related effects on embryonic development of the Mediterranean locust, Dociostauru maroccanus. Physiol. Ent., 25: 191-195. https://doi.org/10.1046/j.1365-3032.2000.00185.x

Roy, D.B. and Sparks, T.H., 2000. Phenology of British butterflies and climate change. Glob. Chang. Biol., 6: 407-416. https://doi.org/10.1046/j.13652486.2000.00322.x

Raworth, D.A. and Schade, D., 2006. Life history parameters and population dynamics of Ericaphs fimbriata (Hemiptera: Aphididae) on blueberry, Vaccinium corymbosum. Can. Entomol., 138: 205-217. https://doi.org/10.4039/n05-021

Southwood, T.E. and Henderson, P.A., 2000. 
Ecological methods. Third Edition. Blackwell Sciences, Oxford, pp. 592.

Schimel, D.S, Kittel, T., Knapp, A.K., Seastedt, T.R., Parton, W.J. and Brown, V.B., 1991. Physiological interactions along resource gradients in a tall grass prairie. Ecology, 72: 672-684. https://doi. org/10.2307/2937207

Sedaratian, A., Fathipour, A.Y., Talebi, A.A. and Farahani, S., 2010. Population density and spatial distribution pattern of Thrips tabaci (Thysanoptera: Thripidae) on different soybean varieties. J. agric. Sci. Technol., 12: 275-288.

Symmons, P., 2009. A critique of Preventive control and desert locust plagues. Crop Prot., 28: 905-907. https://doi.org/10.1016/j.cropro.2009.04.012

Taylor, L.R., 1961. Aggregation, variance and mean. Nature, 189: 732-735. https://doi. org/10.1038/189732a0

Taylor, L.R., 1984. Assessing and interpreting the spatial distributions of insect populations. Annu. Rev. Ent., 29: 321-357. https://doi.org/10.1146/annurev. ento.29.1.321

Xiong-Bing, T., Song, G., Yasen, S., Xiang, Q.N., Guang, J.W. and Hua, Z.Z., 2010. Effects on eating and food utilization efficiency of Locusta migratoria manilensis (Meyen) at different temperatures. Chin. Bull. Ent., 47: 690-693.

Tu, X., Li, Z., Zhang, Z., Wu, Z., Ni, W., Fu, L., and
Shali, Y., 2012. The potential geographical distribution of Locusta migratoria tibetensis Chen (Orthoptera: Acrididae) in Qinghai-Tibet Plateau. In: International Conference on Computer and Computing Technologies in Agriculture. Springer Berlin Heidelberg. pp. 343-351. https://doi. org/10.1007/978-3-642-36137-1_40

White, E.G., 1974. A quantitative biology of three New Zealand alpine grasshopper species. N. Z. J. agric. Res., 17: 207-227. https://doi.org/10.1080/0028823 3.1974.10421001

Wu, F.Z., Ma, S.J. and Zhu, H.F., 1990. Oriental migratory locust. Encyclopedia of Agriculture in China, Hexapod Book, China Agriculture Press, Editorial Board of the Encyclopedia of Agriculture in China, Beijing, pp. 73-78.

Yang, Q., Liaozhi, C. and Lee, Q., 2008. Feeding habits and economic threshold of Locusta migratoria tibetensis Chen. Acta Phytophyl. Sin., 35: 399-404. (in Chinese)

Yao, T.D., Liu, X.D., Wang, N.L. and Shi, Y., 2000. Amplitude of climatic changes in Qinghai Tibetan plateau. Chin. Sci. Bull., 45: 1236-1243. https://doi. org/10.1007/BF02886087

Yu, G., Shen, H. and Liu, L., 2009. Impacts of climate change on historical locust outbreaks in China. $J$. Geophys. Res.: Atmospheres, 114: (D18). https://doi. org/10.1029/2009JD011833 